\title{
La fin du pouvoir provincial (4 août 1789-21 septembre 1791)
}

\section{Marie-Laure Legay}

\section{(2) OpenEdition \\ 1 Journals}

\section{Édition électronique}

URL : https://journals.openedition.org/ahrf/821

DOI : 10.4000/ahrf.821

ISSN : 1952-403X

Éditeur :

Armand Colin, Société des études robespierristes

Édition imprimée

Date de publication : 1 juin 2003

Pagination : 25-53

ISSN : 0003-4436

\section{Référence électronique}

Marie-Laure Legay, «La fin du pouvoir provincial (4 août 1789-21 septembre 1791) », Annales

historiques de la Révolution française [En ligne], 332 | avril-juin 2003, mis en ligne le 22 avril 2008, consulté le 23 avril 2022. URL : http://journals.openedition.org/ahrf/821 ; DOI : https://doi.org/ 10.4000/ahrf.821 


\title{
LA FIN DU POUVOIR PROVINCIAL (4 AOÛT 1789-21 SEPTEMBRE 1791)
}

\author{
MARIE-LAURE LEGAY
}

\begin{abstract}
L'histoire de la province prit fin entre le 4 août et le 22 décembre 1789, lorsque les députés de l'Assemblée nationale adoptèrent le principe d'une division uniforme du royaume. Néanmoins, elle survécut administrativement au-delà de cette période, jusqu'au décret du 21 septembre 1791 supprimant les commissariats formés dans les anciennes provinces d'États. Ainsi, du 4 août 1789 au 21 septembre 1791, nous pouvons suivre les aléas de son histoire, non plus comme entité politique mais comme cadre d'administration. En effet, ses instances exécutives durent être prolongées pour éviter une dangereuse vacance du pouvoir. En attendant la formation effective des départements, if fallut imaginer des commissions provisoires capables de représenter l'autorité fiscale dans la province, les doter de compétences importantes, susceptibles de maintenir l'ordre face à des populations agitées, trouver et encourager des hommes de bonne volonté dont la légitimité politique était pourtant compromise par les élections. Bref, il fallut, à Dijon, à Cambrai, à Aix, à Lille, à Montpellier... garantir la continuité de l'État au moment où ses bases étaient fondamentalement remises en cause. Le maintien des exécutifs provinciaux, concurrents des nouvelles administrations de département et de district, provoqua en certains endroits des remous politiques, reflets d'une contradiction des pouvoirs au plus haut sommet de l'État. Tandis que les anciens administrateurs firent valoir leurs lettres de commissions, les nouveaux en appelaient à l'Assemblée nationale pour faire révoquer les pouvoirs de leurs concurrents. La mauvaise volonté des premiers, associée à l'impatience des seconds, au demeurant légitime, pour gouverner leur circonscription, entretint un climat délétère qui compliqua pour le moins la transition administrative.
\end{abstract}

Mots clés : commissariat de département; commission intermédiaire; recouvrement fiscal; transition administrative; Bourgogne; Bretagne; Cambrésis ; Languedoc ; Provence.

La province connut son heure de gloire entre le 17 juin 1787, date de l'édit formant les assemblées provinciales et la mi-février 1789, lorsque le roi refusa toute représentation particulière des pays d'États aux États généraux. Entre ces deux dates, le Hainaut d'abord, puis la Provence, le Dauphiné, la Franche-Comté..., parvinrent à faire valoir leur existence politique, tandis 
qu'une généralisation des assemblées d'États était envisagée dans les bureaux ministériels. La province comme entité politique jetait là ses derniers feux. Son histoire prit fin entre le 4 août et le 22 décembre 1789, lorsque les députés de l'Assemblée nationale adoptèrent le principe d'une division uniforme du royaume. Néanmoins, la province survécut administrativement au-delà de cette période, jusqu'au décret du 21 septembre 1791 supprimant les commissariats formés dans les anciennes provinces d'États. Ainsi, du 4 août 1789 au 21 septembre 1791, nous pouvons suivre les aléas de l'histoire de la province, non plus comme entité politique, mais comme cadre d'administration. En effet, ses instances exécutives durent être prolongées pour éviter une dangereuse vacance du pouvoir. En attendant la formation effective des départements, il fallut imaginer des commissions provisoires capables de représenter l'autorité fiscale dans la province, les doter de compétences importantes, susceptibles de maintenir l'ordre face à des populations agitées, trouver et encourager des hommes de bonne volonté dont la légitimité politique était pourtant compromise par les élections. Bref, il fallut, à Dijon, à Cambrai, à Aix, à Lille, à Montpellier... garantir la continuité de l'État au moment où ses bases étaient fondamentalement remises en cause. Le maintien des exécutifs provinciaux, concurrents des nouvelles administrations de département et de district, provoqua en certains endroits des remous politiques, reflets d'une contradiction des pouvoirs au plus haut sommet de l'État. Tandis que les anciens administrateurs firent valoir leurs lettres de commissions, les nouveaux en appelaient à l'Assemblée nationale pour faire révoquer les pouvoirs de leurs concurrents. La mauvaise volonté des premiers, associée à l'impatience des seconds, au demeurant légitime, pour gouverner leur circonscription, entretint un climat délétère qui compliqua pour le moins la transition administrative.

Nous conterons donc l'histoire d'un échec, celui d'une passation du pouvoir dans les anciennes provinces d'États. Nous présenterons d'abord les instances exécutives opérationnelles en 1789, 1790 et 1791 (certaines provinces, comme le Languedoc, connurent trois types de commissions différentes en trois ans), les pouvoirs qui leur furent attribués, et les hommes qui servirent de relais administratifs. Nous observerons ensuite les conflits générés par cette situation paradoxale, où légitimité politique et réalité du pouvoir n'étaient pas placées dans les mêmes mains. Les anciens administrateurs exprimèrent bien quelques revendications de nature "provincialiste", néanmoins, leur motivation s'émoussa rapidement face aux protestations des nouveaux représentants. Enfin, nous tenterons d'évaluer le travail effectué au cours de cette période : malgré les moyens déployés, le recouvrement fiscal fut médiocre, les comptes inexistants, et l'inventaire des papiers incomplet. 


\section{Le maintien du pouvoir exécutif provincial}

\section{Des instances pour représenter «l'universalité» de la province}

La transition du pouvoir exécutif provincial se fit en trois temps. Avant le printemps 1790 , le gouvernement put s'adresser aux organes exécutifs traditionnels, c'est-à-dire les commissions intermédiaires dans les pays où des assemblées provinciales avaient été établies, et les bureaux permanents dans les pays d'États (1). Sous l'Ancien Régime, ces instances administraient la province entre deux assemblées générales. Elles exécutaient les délibérations prises par ces dernières et rendaient compte par devant elles de leurs travaux. Le 15 octobre 1788, les assemblées provinciales furent ajournées dans tout le royaume. Entre janvier et avril 1789, les États provinciaux s'éteignirent à leur tour. Ceux de Bretagne furent suspendus le 3 janvier, la brève existence des États de Franche-Comté prit fin le 6, la dernière assemblée des États d'Artois eut lieu le 3 mars, la porte de la salle des États de Flandre wallonne fut solennellement fermée le 9 mars, les États du Hainaut se réunirent pour la dernière fois le 21 avril. Malgré l'ajournemient de ces assemblées, les commissions intermédiaires restèrent en activité, soumises unilatéralement aux ordres du pouvoir royal à partir de ces dates, sans plus avoir de compte à rendre aux assemblées dont elles étaient issues. Le gouvernement dut faire savoir qu'il déléguait l'autorité exécutive aux anciens administrateurs des provinces. Ce fut le cas pour les assemblées diocésaines du Languedoc dont les attributions firent l'objet d'une proclamation du roi du 27 octobre 1789. Les administrateurs patentés des bureaux permanents administrèrent donc la province jusqu'au printemps 1790 , en restant dans l'attente d'une résolution définitive de leur sort. Les lettres patentes du 21 janvier 1790 confirmèrent leur utilité en les autorisant à rendre exécutoires les rôles d'imposition. De même, le décret du 30 janvier 1790 relatif aux recouvrements et aux versements des impositions de 1790 conservait l'ancienne division des provinces là où elle demeurait nécessaire. Enfin, le décret du 26 février stipulait, en son article 4, que les anciennes divisions relatives à la perception des impôts et au pouvoir judiciaire subsistaient jusqu'à ce qu'il en ait été autrement ordonné. Ainsi, parce qu'ils disposaient de la compétence fiscale, les bureaux exécutifs des pays d'États voyaient leur existence encore prolongée de quelques mois.

Pour asseoir leur autorité, il fallut néanmoins spécifier davantage leurs pouvoirs. C'est pourquoi, le 14 février, une proclamation du roi confia les

(1) Les noms variaient d'un pays d'États à l'autre : «bureau permanent » dans le Cambrésis, « députation ordinaire " en Artois, "commission intermédiaire » en Bretagne et dans le Béarn, "procure d'Aix » en Provence, «syndics généraux » en Languedoc, "élus » en Bourgogne. Marie-Laure LEGAY, Les États provinciaux dans la construction de l'État moderne aux XVIre et XVIfe siècles, Genève, Droz, 2001, 565 p. 
rôles d'imposition aux anciens administrateurs des provinces d'Artois, de Flandres, du Cambrésis et du Hainaut. Le 10 mars 1790, un décret ordonna aux anciens procureurs des pays de Provence de continuer d'administrer la province. Le député Bouche avait en effet expliqué que cette province restait sans administration tant que les membres des départements n'étaient pas en mesure d'exercer leurs fonctions (2). De même, le 23 mars, l'Assemblée nationale décréta la formation d'une nouvelle "commission provisoire » en Languedoc pour former l'assiette des impositions de 1790 :

«L'Assemblée nationale, considérant que les États et les administrations secondaires de la province du Languedoc sont supprimés, qu'il n'y a point de commission intermédiaire dans cette province, et qu'enfin une administration provinciale est nécessaire pour assurer l'exécution des décrets des 12 et 13 janvier dernier, qui prescrivent la forme de la perception et du recouvrement des impositions de la précédente année dans les pays d'États, a décrété et décrète ce qui suit : article 1er : il sera rétabli dans la province de Languedoc une commission provisoire composée de huit personnes domiciliées dans la province et nommées par le roi.» (3)

Outre cette commission principale établie à Montpellier, le décret créait des commissions secondaires dans chaque diocèse, composées de cinq membres. Ces commissions secondaires faisaient cesser l'administration des assemblées diocésaines, mais ne mettaient pas fin au service des syndics des diocèses qui restèrent en activité pour les objets autres que les impositions. De même, le syndic général du Languedoc, Jean-Baptiste Rome, fut maintenu en place auprès de la commission principale. Quelques jours plus tard, le 11 avril, le cas bourguignon dut également être réglé par l'Assemblée nationale. Une commission particulière réactiva donc la chambre des Élus de Bourgogne pour l'administration des impositions, attribuant par ailleurs à ces élus d'Ancien Régime la faculté de statuer sur les réclamations des imposés... On voit par là qu'il fallut, dans le courant du printemps 1790, remédier au plus vite à la vacance du pouvoir qui s'annonçait dans les provinces d'États. En renouvelant les commissions des anciens administrateurs, l'Assemblée insistait certes sur leur caractère provisoire. Les hommes en exercice devaient tôt ou tard céder leur place aux commissaires de départements prévus par la loi sur les nouvelles administrations. Elle n'en révélait pas moins la gêne dans laquelle elle se trouvait, donnant la légitimité politique aux uns, et la réalité du pouvoir sur les administrés aux autres. En

(2) Archives parlementaires, première série, tome XII, p. 108.

(3) Id. première série, tome XII, p. 329. Les huit membres de la commission furent Messieurs Chauliac, officier municipal à Toulouse, pour le département de Haute-Garonne; l'abbé Gauzy, doyen du chapitre de Castelnaudary à Carcassonne, pour le département de l'Aude; Soubeyran, pour la HauteLoire; Sicard, conseiller à la cour des aides de Montpellier, pour l'Hérault; Boissier de Sauvages, pour le département du Gard; Boyer, négociant et substitut du procureur de la commune d'Albi pour le Tarn, de L'Hermet, ancien syndic, pour la Lozère; Barruel, lieutenant général de la sénéchaussée de Villeneuve-deBerg pour l'Ardèche. 
avril 1790, le gouvernement s'adressait donc encore aux «députés ordinaires» des États d'Artois, au «bureau permanent» des États du Cambrésis, aux «chefs-collèges » de Flandre maritime, aux "grands baillis » de Flandre wallonne, aux "syndics généraux» des États de Navarre, du Nébouzan, des pays des Quatre vallées, de Marsan et de Labour, aux syndics des pays de Gex, du Bugey et de la Bresse, aux «élus » de Bourgogne, à la "procure » d'Aix, aux commissions du Béarn, de la Soule, de la Bigorre et du pays de Foix et à une commission provisoire du Languedoc (4). Il n'y avait guère que cette dernière administration qui manifestait concrètement le changement de régime institutionnel dans les provinces à cette époque.

Cette deuxième phase, la plus orageuse sur le plan politique, prit fin à l'automne 1790, période au cours de laquelle les départements entrèrent en activité. Les bureaux exécutifs provinciaux furent remplacés par des commissariats de département en vertu de l'article 10 de la section III du décret du 22 décembre 1789. Ces commissariats avaient été prévus pour la Bretagne, la Bourgogne, le Languedoc et la Provence. À Dijon, le commissariat, "représentant la consistance de l'ancienne province de Bourgogne ", commença ses travaux très tôt; le 7 juillet 1790 , en prenant place dans le palais des États (5). Cette précocité s'explique par la célérité avec laquelle s'étaient organisés les départements eux-mêmes. À Montpellier, les vingt commissaires des dix départements formés dans l'ancienne province de Languedoc (Ardèche, Ariège, Aude, Gard, Haute-Garonne, Haute-Loire, Hérault, Lozère, Pyrénées-Orientales, Tarn, à raison de deux commissaires par département) s'assemblèrent onze mois et demi, du 15 septembre 1790 au 31 août 1791. Selon le procès-verbal de leurs séances, certains s'attelèrent sérieusement à leur tâche, comme le commissaire de l'Hérault, Cambon, qui siégea 288 jours avant de partir pour l'Assemblée nationale; d'autres furent moins assidus comme le commissaire de Haute-Garonne, Mieulet de La Rivière, qui ne fournit que 49 jours de travail (6). En dehors des quatre provinces citées par le décret du 22 décembre 1789, les affaires provinciales furent également liquidées par des commissaires de départements, sans que ceux-ci ne forment une administration particulière. En effet, l'article 3 des lettres patentes du 2 juillet 1790 réglant la mise en activité des nouvelles administrations, précisait que les membres de ces administrations devaient se réunir tous en session de conseil le 15 septembre pour les districts, et le 1 er octobre pour les départements, mais qu'ils étaient autorisés à nommer des commissaires chargés de la liquidation des affaires générales avant ces dates. Ainsi dans le Nord, deux commissaires du département furent chargés des papiers de l'intendance du Hainaut, deux autres des papiers des

(4) A.N., H1 1469, pièce 123, note du 22 avril 1790.

(5) Ibid., $\mathrm{H}^{1} 201^{2}$, pièce 23, procès-verbal du Commissariat des départements de Bourgogne.

(6) $\mathrm{lbid}$. , H1 995, pièce 2, procès-verbal du Commissariat des départements du Languedoc, 1655 p. 
États du Cambrésis, deux s'attelèrent aux archives de l'intendant de Flandre et des États de Flandre wallonne, et enfin deux autres à celles de l'administration de Flandre maritime. Dans le Pas-de-Calais, un seul commissaire fut nommé, l'avocat Lesage, pour recevoir les papiers des anciens États d'Artois (7). Le décret du 21 septembre 1791 mit fin à tous les commissariats des provinces d'États, et par là même à la consistance administrative de celles-ci (8).

\section{Des attributions soustraites aux départements}

Nous ne nous attarderons pas sur les attributions des bureaux exécutifs provinciaux avant la formation des départements, car s'intéresser aux compétences administratives des commissions intermédiaires, c'est revoir toute l'histoire des États provinciaux et des assemblées provinciales, ce qui ne saurait entrer dans le cadre de notre analyse. Remarquons cependant que sous l'Ancien Régime, au fil des décennies, le cadre d'administration provincial avait confirmé son utilité pour toute une série de prérogatives : la répartition et la levée des impôts certes, mais aussi les travaux publics (routes et canaux) ou la politique économique et sociale (soutien aux manufactures, traitement de la mendicité, ateliers de charité, secours de bienfaisance, formation d'écoles de dessin, de chirurgie, d'obstétrique...). Il fallait donc expédier de nombreuses affaires courantes. Certaines ne posèrent pas de difficultés au moment de leur transmission aux départements; d'autres en revanche, comme les attributions fiscales ou l'aménagement du territoire, furent vivement disputées entre anciens et nouveaux administrateurs. Le pouvoir central dut donc clarifier les compétences et donner des instructions précises au fur et à mesure des changements d'exécutifs locaux.

L'application des premiers décrets financiers de l'Assemblée nationale, notamment ceux pour la réduction du prix du sel et l'imposition des biens privilégiés sur les six derniers mois de l'année 1789 (23 et 25 septembre 1789), fut clairement attribuée aux commissions intermédiaires des provinces (9). Dans la crainte que le peuple ne se soustraie aux impôts, on les encouragea à donner toute la publicité nécessaire à ces nouvelles dispositions :

(7) A.D.N., L 764, mémoire adressé à l'Assemblée nationale par les administrateurs composant le directoire du département du Nord, septembre 1790, et C 15 913, lettre des administrateurs composant le directoire du département du Pas-de-Calais, 27 août 1790.

(8) Archives parlementaires, première série, tome XXXI, p. 130, article 16.

(9) Id., première série, tome IX, p. 125 (23 septembre 1789) et p. 186 (25 septembre). Les articles 1 et 2 du décret sur la gabelle furent ainsi rédigés : «Les administrations provinciales, les juridictions et les municipalités du royaume veilleront aux moyens d'assurer le recouvrement des droits subsistants. La gabelle sera supprimée aussitôt que le remplacement en aura été concerté et assuré avec les assemblées provinciales». 
«Ce n'est que par le concours de toutes les personnes qui sont revêtues d'un caractère public que Sa Majesté peut espérer le rétablissement de l'ordre... Il faut donc que les commandants des Provinces, les intendants, les représentans intermédiaires des États et les municipalités agissent de concert. » (10)

Cependant, lorsque le procureur syndic de la province d'Anjou, par ailleurs député à l'Assemblée constituante, sollicita un congé de celle-ci, afin d'aller travailler à la confection des rôles, ses confrères l'enjoignirent de demeurer à Paris, pour satisfaire avant tout à son devoir de représentant de la nation (11). Après l'organisation des nouvelles administrations (décret du 22 décembre 1789 et lettres patentes de janvier 1790), il fallut prendre de nouvelles dispositions en autorisant ces mêmes commissions intermédiaires à rendre exécutoires les rôles d'imposition (lettres patentes du 21 janvier 1790). À cette date, les chambres exécutives provinciales remplissaient leur rôle avec constance. Pour faciliter la confection des rôles supplétifs, les Élus de Bourgogne rédigèrent par exemple plusieurs instructions (12). Ils furent en effet confrontés aux nombreuses interrogations des municipalités sur la manière dont les privilégiés devaient être taxés, la localisation de leurs biens, le tarif auquel ils devaient être soumis, les personnes aptes à confectionner ces rôles de supplément...

L'exécution du décret sur la contribution patriotique (6 octobre 1789) posa davantage de problèmes. Le gouvernement espérait. bien pouvoir compter sur les anciens corps restés en exercice. Le 10 octobre 1789, Necker écrivait aux États du Cambrésis :

«Vous aurez bientôt à vous occuper d'un autre objet non moins important, auquel le Roi est bien convaincu que vous concourrez de tout votre pouvoir, je veux parler de la contribution du quart de tous les revenus que l'Assemblée nationale a décrétée. " (13)

Pourtant, certaines commissions, comme celle de Bretagne, refusèrent de s'atteler à cette tâche, considérant qu'elles ne devaient rendre compte qu'aux seuls États provinciaux. Ce refus provoqua le mécontentement du ministre Lambert qui en écrivit à l'intendant de Rochefort :

«Messieurs les commissaires intermédiaires n'ont pas fait attention qu'il s'agit ici de l'exécution d'un décret de l'Assemblée nationale sanctionné par le Roi, lequel est obligatoire pour la Bretagne comme pour les autres provinces... Monsieur Necker, en leur proposant de se charger de l'exécution de ce décret, avoit cru leur fournir une nouvelle occasion de marquer leur zèle par la manière dont ils auroient concouru au succès des vues du roi... " (14)

(10) A.D.N., C 15 902, lettre du contrôleur général aux États du Cambrésis, 10 octobre 1789.

(11) Archives parlementaires, première série, tome IX, p. 450, demande de monsieur Dieuzie.

(12) A.N., H1 2011, par exemple pièce 41 : Nouvelle instruction concernant la confection des rôles de supplément des ci-devant privilégiés pour les six demiers mois de l'année 1789, s.l.n.d., [juin 1790], 23 p.

(13) Voir note 10.

(14) A.N., H11483, pièce 507, lettre du 15 novembre 1789. 
Le bureau permanent des États du Cambrésis et la procure d'Aix eurent la même attitude rétive. Certes, l'entremise des commissions intermédiaires n'était pas absolument nécessaire pour l'exécution du décret sur la contribution patriotique, puisque celui-ci chargeait surtout les municipalités de former les listes. L'échelon provincial n'était utilisé que pour la supervision des opérations (15). Cependant, la mauvaise volonté des exécutifs provinciaux retarda sans nul doute la levée et le ministre dut encore admonester les administrateurs récalcitrants sur ce sujet au cours du printemps 1790 (16). D'autres commissions firent preuve de plus de compréhension. Les Élus généraux de Bourgogne, par exemple, adoptèrent un plan qui reçut l'éloge du ministre :

«Je ne puis qu'approuver le plan que votre zèle vous a suggéré à cet égard. J'applaudis de même à la détermination que vous avez prise de vous charger de la confection des rôles. C'étoit le meilleur moien non seulement d'en assurer l'exactitude et l'uniformité, mais encore d'en accélérer la rédaction. » (17)

Globalement, cependant, le concours des anciennes instances exécutives ne présentait rien d'assuré. De fait, le décret du 2 novembre sur les biens ecclésiastiques, en attribuant aux administrations provinciales et municipales la perception des dîmes, parut irréaliste (18) et les choses se compliquèrent lorsqu'il fallut envisager la reconduite des anciens impôts, tant directs qu'indirects, pour l'année 1790. À qui la compétence fiscale allait-elle être confiée? Pour pallier l'inorganisation des départements, l'Assemblée nationale dut, nous l'avons vu, réactiver les administrations permanentes des anciennes provinces d'États. En Languedoc, tandis que les rôles supplétifs de 1789 et la contribution patriotique avaient été confiés aux syndics et commissaires ordinaires des diocèses, les impositions de 1790 le furent à des commissions provisoires (19). En vertu du décret du 23 mars 1790 , celles-ci se chargèrent précisément de faire la répartition de l'impôt dans toute la province, «en la forme accoutumée " et « sans déplacer » (20). Les impôts de la province portaient sur un total de quinze millions. Les commissaires ne chômèrent pas. Ils rendirent près de 2000 jugements de vérification en faveur des municipalités ou des diocèses et réglèrent de nombreuses contestations concernant les vingtièmes. Ils annoncèrent par

(15) Archives parlementaires, première série, tome IX, décret du 6 octobre, article 18 : «Chaque municipalité sera tenue d'informer les administrations de la province de l'exécution successive des dispositions arrêtées par le présent décret, et ces administrations en rendront compte à un comité composé du ministre des Finances et des commissaires qui seront nommés par l'Assemblée nationale ».

(16) A.D.N., C 15 906, lettre de Claude Lambert au bureau permanent des États du Cambrésis, 20 avril 1790.

(17) A.N., $\mathrm{H}^{1}$ 1483, feuille đe travail du commis Harivel, 14 décembre 1789.

(18) Archives parlementaires, première série, tome IX, pp. 648-649, article 10.

(19) A.N., H1 997, pièce 100.

(20) Archives parlementaires, première série, tome XII, p. 329. 
ailleurs vouloir établir un bureau de la capitation. La réaction des nouvelles municipalités les en empêcha (21). Celles-ci n'étaient-elles d'ailleurs pas en droit de contester cette administration provinciale, alors qu'au même moment, le décret du 22 mars 1790 portant sur la contribution des villes en remplacement de la gabelle et autres droits organisait une voie hiérarchique par les directoires de district et de département (22) ? La répartition et la levée des impôts supposaient par ailleurs la possibilité, pour les anciens administrateurs, d'instruire les requêtes s'y rapportant, d'accorder des remises aux particuliers, des rabais aux adjudicataires des fermes... toute intervention susceptible d'être mal jugée par les tenants du nouveau régime. Nous reviendrons sur les contestations des pouvoirs octroyés aux exécutifs provinciaux. L'on comprend d'ores et déjà le soulagement que procura la mise en activité des départements auxquels furent transférées les compétences fiscales, en vertu des instructions adressées successivement aux différentes assemblées.

Outre les impôts, les exécutifs locaux successifs durent encore pourvoir au paiement des intérêts et capitaux exigibles. En Languedoc, les gros volumes de registres contenant les noms des créanciers de la province passèrent ainsi de commission en commission. 16060 mandements devaient être expédiés chaque année en janvier, représentant un total de 5268729 livres pour 1790 (23). Le trésorier des États de Bourgogne, de Montigny, régla les arrérages des emprunts pour 1790 , mais s'inquiéta de ses obligations pour 1791 (24). L'Assemblée nationale libéra les anciens administrateurs provinciaux de cette lourde tâche en décrétant dettes nationales toutes les dettes des pays d'États le 12 avril 1791, et en ordonnant le 21 septembre suivant, que les créanciers des ci-devant pays d'États seraient payés de leurs intérêts jusqu'au 1er janvier 1792 par les payeurs, receveurs ou trésoriers qui en étaient précédemment chargés, et qu'à partir de cette date les rentes reconverties seraient payées par les districts (25). Les travaux publics nécessitèrentt également des éclaircissements pour garantir la continuité de l'administration. Normalement, les anciens bureaux continuèrent l'entretien courant des ouvrages jusqu'à la formation des départements. L'on vit ainsi les députés permanents des États du Cambrésis autoriser leur directeur de travaux, Richard, à poursuivre les aménagements prévus pour les casernes de cavalerie, les greniers et magasins particuliers des États, les digues, berges, portes des rivières et des canaux... jusqu'en juillet 1790 . Les directoires de département devaient prendre la suite.

(21) A.N., $H^{1} 9972$, pièces 31 à 36, juillet 1790 . $1790,4 \mathrm{p}$

(22) Ibid., H1 1469, pièce 86. Lettres patentes du roi sur le décret de l'Assemblée nationale du 22 mars

(23) Ibid., H1 997 , pièce 44.

(24) Ibid, H1 1469. Lettre de Rigoley de Montigny, 22 octobre 1790.

(25) Archives parlementaires, première série, tome XXXI, p.129, article 1. 
On notera que les pouvoirs des commissariats de département prévus pour la Bretagne, la Bourgogne, le Languedoc et la Provence furent limités à trois objets : la liquidation des dettes contractées sous l'Ancien Régime, leur répartition entre les différentes parties de la province et l'expédition des anciennes affaires. Il fut clairement établi que les commissariats ne prendraient pas la suite des affaires provinciales. Celles-ci revenaient aux départements proprement dits. Cependant, bien des dossiers en instance, en rapport notamment avec les travaux publics, nécessitaient encore à l'été 1790 un cadre d'administration incluant plusieurs départements. C'est pourquoi les anciens administrateurs eurent tendance à attendre l'organisation des commissariats avant de transmettre leurs pouvoirs. Les Élus généraux de Bourgogne sollicitèrent un décret de l'Assemblée nationale dans ce sens :

«Toutes ces opérations et celles qui nous sont confiées tiennent encore et doivent tenir pour cette année à l'unité du régime. Les commissaires seront secondés par les différents départements et par les districts et il sera possible d'éviter une confusion générale. Nous serons suffisamment récompensés de nos travaux si le nouvel ordre des choses fait le bonheur, ou du moins assure la tranquillité d'une province que nous avons bien servie. » (26)

De même, le département de l'Hérault reprocha au commissariat général du Languedoc de s'occuper abusivement de confection d'ouvrages et d'ordonner à ce titre des paiements, toute activité qui relevait des compétences des seuls départements en vertu de leurs instructions (27). Par ailleurs, le procès-verbal des séances du commissariat du Languedoc fait apparaître que les impositions de 1789 et 1790 avaient été supervisées par les commissaires.

\section{Les anciens administrateurs maintenus par le gouvemement}

Pour maintenir son autorité, l'État fit attention à ce que les exécutifs demeurent en place aussi longtemps que les affaires, dont ne pouvaient se saisir les départements ou les districts, n'étaient pas réglées. Il dut parfois imposer le silence aux nouveaux élus et faire respecter les ordres des anciens agents dont il avait continué les fonctions. Il enjoignit par exemple le directoire du district de Cambrai à respecter le bureau des États du Cambrésis jusqu'à l'extrême fin de son existence, fixée au 15 septembre 1790. Ce bureau était composé de deux membres du clergé, de deux nobles et de deux représentants de l'ancien Magistrat de Cambrai (28). Dans le

(26) A.N., H1 2012, pièce 70. Copie d'une lettre écrite par les élus généraux de Bourgogne aux présidents des différents comités de l'Assemblée nationale, 22 juin 1790.

(27) Ibid, $\mathrm{H}^{1} 997^{2}$, pièce 98 .

(28) Il s'agissait de l'abbé de Vaucelles, du chanoine Biré, de Michel-Joseph de Villavicencio et Louis-Charles-Ignace Van Cappel de la Nieppe, de Louis-François Lefevre et Delaplace fils. 
même ordre d'idées, le gouvernement refusa le congé de plusieurs commissaires du Languedoc, jugeant trop dangereux de le permettre avant que les vingtièmes n'aient été levés dans cette province (29). L'abbé de Gauzy vit sa demande rejetée, comme le dénommé Chauliac, officier municipal de Toulouse, également membre de la commission provisoire. Ce dernier avait été capitoul et commissaire aux États du Languedoc. Il connaissait donc bien les affaires provinciales et était jugé très utile pour remplir les missions de la commission. Les ministres n'avaient cependant pas le pouvoir de maintenir les anciens agents en place contre le gré des citoyens. Ils ne pouvaient alors que regretter le départ de certains d'entre eux, comme celui du syndic du Vivarais, de Lachadenède, remplacé par le procureur syndic du département de l'Ardèche, Dalmas. Le premier reçut un vibrant hommage de la part du ministère des Finances :

«On a lieu d'être surpris que ce syndic ait abdiqué le travail relatif à la contribution patriotique dont il étoit convenu de laisser la continuation à ceux qui l'ont commencé. On profitera de cette circonstance pour observer que le sieur de Lachadenède jouit dans sa province d'une considération qui l'auroit sans doute porté à la place du sieur Dalmas sans la prévention qui écarte aujourd'hui les agens de l'ancienne administration du Languedoc... Il est fâcheux de voir l'administration privée de pareils coopérateurs. "

En Bourgogne, le gouvernement se servit utilement du vicomte de Bourbon-Busset jusqu'en 1791, avant de l'employer comme colonel dans le régiment Artois Cavalerie. Élu général et commandant de Bourgogne, le vicomte assura pratiquement à lui seul la transition du pouvoir provincial à Dijon. Il tenait la correspondance avec les bureaux ministériels et les nouveaux corps administratifs. Il y faisait sentir son dévouement absolu, ainsi que celui de ses confrères :

«Pour nous, Monsieur, nous avons été assés heureux pour soutenir un édifice chancelant, attaqué de toute part et par toute sorte de moyens. Nous n'aspirons qu'à une retraite honorable et nous voudrions que les formes qui seront réglées pour la remise des affaires nous missent à l'abri, dans notre retraite, de ces inculpations odieuses qui, bien que dénuées de tout fondement, offensent la délicatesse. Nous ne chercherons point, Monsieur, à prolonger nos fonctions. Les circonstances exigent que je vous donne à ce sujet les assurances les plus positives; mais nous désirons en quittant l'administration, nous assurer des droits inattaquables à la considération qui est au moins due à des administrateurs qui se sont constamment occupés de leurs devoirs, du bien public et qui sont aussi bons citoyens que sujets fidèles. » (30)

(29) A.N., H1 997, pièce 39, 16 septembre 1790.

(30) $\mathrm{Ibid}$, $\mathrm{H}^{1} 201^{1}$, pièce 36. Lettre du vicomte Bourbon-Busset au ministre des Finances, 17 juin 1790. 
Dans toutes les provinces, le rôle des employés des anciennes administrations fut déterminant. Greffiers, trésoriers, procureurs, directeur des travaux publics... furent bien souvent les derniers à se maintenir en activité. Par exemple, le greffier des États du Cambrésis, Louis Hubert, exerça ses fonctions jusqu'en août 1790. Ces employés parvinrent parfois à s'établir dans les nouvelles instances, ce qui facilitait la transition administrative. Le célèbre syndic des États du Béarn, le baron d'Angaïs, Jean-Louis de Navailles, devint maire de Pau le 4 février 1790. Le greffier des États du Languedoc, Bonnemain, fut maintenu auprès de la commission provisoire de Montpellier. De même, l'un des secrétaires en chef de l'intendant du Languedoc, Dupin, fut nommé procureur général syndic du département de l'Hérault en juillet 1790. François-Claude Pajot, après avoir été premier secrétaire de l'intendant de Lille, puis subdélégué général en charge de la liquidation de l'intendance jusqu'au 3 novembre 1790, obtint, sur recommandation des directoires du département et du district de Lille, une charge de commissaire au tribunal de ce district (31). De son côté, Pierre Renouvin indique que dans quinze départements au moins, les procureurssyndics étaient d'anciens membres des assemblées provinciales instituées en $1787(32)$.

Néanmoins, tous les employés ne pouvaient être assurés de retrouver une place dans les départements et districts. On peut même avancer qu'en général, le renouvellement du personnel, tant politique qu'administratif, fut assez complet. Les anciens États d'Artois disposaient de 110 hommes de main, tandis que ceux de Flandre wallonne faisaient travailler 286 personnes. En août 1790 , le greffier de cette dernière assemblée recommanda au directoire du département du Nord 150 à 160 receveurs, commis, régisseurs «ci-devant nécessaires à notre régime et qui ne [seront] peut-être pas inutiles au vôtre » (33). On ne sait combien furent repris. Pour ceux qui demeuraient sans emploi, le décret du 8 mars 1791 prévut d'accorder un secours de 50 livres par mois (34). Les directoires furent alors chargés de dresser des listes des employés réformés et de les envoyer au Comité des pensions (35).

(31) Ibid., H1 701, pièce 15.

(32) Pierre RENOUVIN, Les Assemblées provinciales de 1787, Paris, 1921, p. 383.

(33) A.D.N., L 455, lettre du greffier Bon Fruict aux administrateurs du département du Nord, 24 août 1790.

(34) Archives parlementaires, première série, tome XXIII, p. 732.

(35) Les directoires pouvaient également secourir d'eux-mêmes les employés non repris. C'est ainsi que le département du Nord, sur avis favorable du district de Douai, secourut de 100 livres Joseph-Marie Roussel, ancien directeur du magasin aux fourrages des États de Flandre wallonne (A.D.N., L 7201. Requête du 26 mars 1791). 
Au terme de cette première partie, l'on perçoit bien qu'en province, l'État administratif connut sa phase la plus critique pendant l'été 1790 , au moment où les anciens bureaux provinciaux n'avaient plus d'existence légale depuis six mois, mais où les départements et districts ne s'étaient pas encore mis en activité. À la suite du décret du 22 décembre 1789 formant les nouvelles administrations, l'Assemblée nationale dut paradoxalement prendre toute une série de mesures pour réactiver les anciennes instances provinciales ou en imaginer de provisoires, leur conserver des pouvoirs exécutifs pourtant cédés par la loi aux nouveaux élus, maintenir en place des hommes de l'Ancien Régime capables de garantir l'ordre et la transition administrative. Forcée par les circonstances, l'Assemblée nationale se devait de garantir la continuité de l'État et se mettait ainsi, par ses décrets, au diapason du gouvernement. Inversement, le pouvoir exécutif dut à plusieurs reprises tenir compte de l'esprit des lois votées à l'Assemblée nationale et s'en faire l'écho dans les provinces. Cependant, en accordant la légitimité politique aux départements, mais la réalité des pouvoirs aux anciennes instances provinciales, les décideurs parisiens avaient créé une situation difficilement tenable. Les conflits d'administration se multiplièrent dans le courant de l'été 1790 et obligèrent le gouvernement à accélérer, nous allons voir comment, la transition administrative.

\section{La cohabitation des pouvoirs provinciaux et départementaux}

Les bureaux exécutifs provinciaux ont-ils profité de la prolongation exceptionnelle de leurs pouvoirs pour agir politiquement? Pour comprendre les conflits d'administration qui se développèrent dans le courant de cette année 1790 , il nous faut avant tout mesurer la motivation des anciens administrateurs continuant à exercer leurs fonctions dans un contexte difficile, avant d'entendre les arguments de leurs contradicteurs fraîchement élus à la tête des nouvelles assemblées.

\section{La tentation "provincialiste" limitée}

Entre le 4 août et le 22 décembre 1789, certaines administrations provinciales gardèrent l'espoir de se voir reconduites, sous une forme ou sous une autre, et continuèrent donc d'agir selon les principes anciens qui les avaient animées jusqu'alors. Ces instances n'admettaient pas le sacrifice fait à l'Assemblée nationale par des députés, certes élus dans le cadre des bailliages, mais guère plus investis que les administrateurs ordinaires du droit de représenter la substance de la province. «Ont-ils pu valablement obliger cette province par leur adhésion aux décrets de cette assemblée?», demandèrent les procureurs du pays de Provence (36). Les mandats poli- 
tiques des bureaux provinciaux couraient toujours en 1789 et concurrençaient directement ceux des députés issus des élections bailliagères. À Versailles, les députés à la cour des provinces concernées décidèrent toutefois de s'abstenir de toutes représentations au roi, d'autant que l'on ne leur permit pas de présenter leurs cahiers annuels de doléances selon les usages habituels (37). Dans les régions en revanche, les décrets de l'Assemblée nationale provoquèrent d'importantes réactions. Dans le Dauphiné, une assemblée fut convoquée pour révoquer les députés parisiens. La noblesse de Bretagne chercha à se réunir à Saint-Malo. Le 10 octobre 1789, quatre-vingt-dix nobles et quatre-vingts parlementaires se concertèrent à Toulouse pour «s'opposer à l'abolition des droits et franchises des provinces et des villes » (38). L'Assemblée nationale poursuivit cependant son œuvre. Le 15 octobre, elle supprima le vote par ordre dans les assemblées bailliagères, en exigeant que l'élection des suppléants se fît par l'ensemble des citoyens inscrits (39). Le 26 octobre, elle interdit toute convocation, par ordre, d'assemblée en province. Les membres des États cambrésiens passèrent outre ces dispositions et convoquèrent une assemblée pour le 9 novembre, aux fins de révoquer les députés de la province à l'Assemblée nationale ! Ce crime de lèse-nation fut vivement dénoncé par Robespierre et Merlin de Douai au cours de la séance du 19 novembre. L'Assemblée nationale déclara nulle la délibération du 9 novembre et mit fin à toute prétention politique du petit cénacle cambrésien (40).

Une fois les intentions des Constituants clairement établies par les décrets sur la nouvelle organisation administrative du royaume, les administrateurs provinciaux cessèrent d'espérer. "Aucune puissance humaine ne peut aujourd'hui faire revenir l'Assemblée nationale contre la disposition de son décret qui ordonne la division des provinces », déclarèrent les membres des États de Cambrai (41). Les démarches visant à rétablir les droits politiques de la province, déjà peu nombreuses avant le 22 décembre 1789 , furent réduites à néant après cette date. Dès lors, les intentions des bureaux exécutifs maintenus par le gouvernement ne pouvaient guère faire de doutes. Il s'agissait bel et bien pour les administrateurs devenus intérimaires, d'assurer une continuité du service, dans l'intérêt des populations. C'est pourquoi les ministres louèrent le désintéressement des agents restés en activité tout au long de l'année 1790, mesurant combien leur tâche pouvait être pénible. Il faut dire que certains d'entre eux, aguerris au

(37) A.D.N., C 15 888, lettre des députés à la cour des États du Cambrésis, 3 septembre 1789. On apprend que les auteurs de la lettre se sont concertés avec d'autres députés provinciaux, notamment ceux du Languedoc et de l'Artois.

(38) Archives parlementaires, première série, tome IX, p. 553, intervention de Lanjuinais.

(39) Id. pp. 450 et 451.

(40) Marie-Laure LEGAY, op. cit., p. 507.

(41) A.D.N., C 15 895, lettre des députés à la cour, 26 novembre 1789. 
traitement des affaires provinciales et interlocuteurs de longue date des bureaux ministériels parisiens, présentaient parfois une culture politique plus étendue que les nouveaux élus.

\section{Les administrateurs légitimes impatients}

Bien des hommes politiques s'opposèrent aux anciens administrateurs. En premier lieu, les députés de l'Assemblée nationale. Timothy Tackett a évoqué la particularité des élus issus des pays d'États (42). Robespierre contre les États d'Artois, Lanjuinais contre les États de Bretagne, Mirabeau contre les États du Languedoc... tous avaient fait campagne contre les représentants provinciaux d'un régime abhorré. Une fois à l'Assemblée, ils restaient vigilants et traquaient toute prétention résiduelle de leurs ennemis. Robespierre intervint par exemple vigoureusement lors de la séance du 28 décembre 1789 à l'origine du décret obligeant les États provinciaux, assemblées provinciales, commissions intermédiaires, intendants et subdélégués à rendre le compte des fonds dont ils avaient eu la disposition (43). Trois jours auparavant, les députés du bailliage de Bailleul avaient obtenu du roi l'autorisation de nommer des commissaires pour faire des recherches sur les revenus et les charges de la province de Flandre maritime (44). Nul doute que la volonté de saisir au plus vite les comptes des anciennes administrations cachait l'intention de dénoncer les abus de l'Ancien Régime. Les bureaux ministériels reconnurent que les commissaires en question «s'étaient livrés à des recherches étrangères à leur mission " (45). Les députés des anciennes provinces d'États ont également, nous l'avons vu, contré toute velléité de rassemblement provincial dans le courant des mois d'octobre et novembre 1789. Plus tard, ils soutinrent les nouveaux élus locaux lorsque ceux-ci eurent à se plaindre des agissements des exécutifs provinciaux.

Premières en place, les nouvelles municipalités ne tardèrent pas à s'opposer à ces exécutifs à propos des impositions dont ils avaient la charge. Certes, citadins et villageois étaient tous impatients de voir cesser les inégalités fiscales, et bien des résistances à l'impôt, direct ou indirect, furent enregistrées dans le courant de cette année 1790. Néanmoins, certaines communautés s'en prirent plus spécifiquement aux instances administratives provinciales. La ville de Béziers adopta par exemple une délibération incen-

(42) Timothy TACKETT, Becoming a Revolutionnary. The Deputies of the French National Assembly and the Emergence of a Revolutionnary Culture (1789-1790), Princeton University Presse, 1996 (trad.: Par la volonté du peuple, Paris, Albin Michel, 1997).

(43) Archives pardementaires, première série, tome XI, p. 32.

(44) A.N., $\mathrm{H}^{1}$ 701, pièces 1,2 et 3 . Les commissaires nommés furent l'abbé Legier, chanoine de la collégiale Saint-Pierre à Cassel, le marquis d'Esquelbecq et messieurs Top et Cousser pour le Tiers État.

(45) Ibid. 
diaire contre la répartition que la commission provisoire du Languedoc avait arrêtée, et la fit parvenir à toutes les municipalités de la province. Elle reprocha à la commission d'avoir trop imposé, et d'avoir distribué des gratifications aux anciens administrateurs pour 1790 (46). Le comte de Périgord, commandant de la province, le baron de Ballainvilliers, intendant, mais aussi les syndics des diocèses ou l'agent des affaires des États... étaient mis en cause. Or, la commission provisoire ne fit que suivre les dispositions des décrets de l'Assemblée nationale qui accordaient des émoluments à ces agents, au prorata du temps passé cette année-là à liquider leur administration. Au même moment cependant, les municipalités de l'Ardèche s'opposèrent à la formation du bureau de capitation prévu par la même commission.

Les élus des départements et districts ne furent pas moins prompts à dénoncer le maintien des exécutifs provinciaux. Les critiques à l'encontre des élus généraux de Bourgogne furent particulièrement virulentes :

«Messieurs les élus raisonnent et agissent comme s'ils formoient encore un corps existant; ils suspendent leurs séances, ils se réservent de se réunir comme si le décret n'en avoit pas prononcé la cessation pour toujours, comme si toute réunion ultérieure n'en devenoit pas une violation formelle; ils commettent leurs secrétaires en chef, comme s'il pouvoit exister des secrétaires d'une administration qui n'existe plus; ils disposent des commis, des bureaux, des deniers même de la province, comme si les directoires des départements n'étoient pas en activité; ils ordonnent la rédaction de tableaux et autres opérations et donnent suite à leurs précédentes délibérations comme si elles avoient été approuvées par les directoires. » (47)

En bref, on soupçonna les élus généraux de Bourgogne de vouloir « arrêter le département de la Côte-d'Or dès ses premiers pas et de l'empêcher de remplir les vues du roi et celles de l'Assemblée nationale» (48). Pour juguler ces critiques, les lettres patentes du 2 juillet 1790 tentèrent de clarifier au mieux l'entrée en activité des départements, fixée au 1er octobre, et celle des districts, fixée au 15 septembre. Néanmoins, la loi n'empêcha pas les empoignades locales. À Mâcon, membres du département de Saône-etLoire et anciens administrateurs du Mâconnais s'affrontèrent à propos de la répartition des impositions. Les premiers avaient pour eux les articles 1 er et 8 de la section III des lettres patentes de janvier 1789 qui les chargeaient spécialement de répartir toutes les contributions directes imposées à chaque département; les Élus du Mâconnais avaient naturellement en leur faveur les décrets autorisant les commissions intermédiaires des pays d'États à rendre exécutoires les rôles d'imposition (49). À Cambrai, les administra-

(46) Ibid, H1 997, pièce 63 : lettre des commissaires, 6 juillet 1790.

(47) Ibid., H1 2022, pièce 40, août 1790 .

(48) $\mathrm{Ibid}$. $\mathrm{H}^{1} 201^{2}$, pièce 87 , copie de la lettre de Monsieur le contrôleur général à monsieur le comte de Saint-Priest, 18 juin 1790.

(49) Ibid., H1 $^{1} 201^{1}$, pièces 52 à 65. 
teurs nommés pour composer le district de cette ville formèrent le directoire le 23 juillet. Le 24 , les membres de ce directoire s'assemblèrent dans une salle qu'ils firent demander aux États, dans un climat politique exalté, entretenu par une «assemblée patriotique » de paysans (50). Ce faisant, ils dénonçaient la poursuite des activités de l'ancienne administration. Ils furent soutenus en cela par l'Assemblée nationale qui avaient déjà condamné cette chambre en novembre 1789 pour délit de lèse-nation. Le 30 juillet 1790, un décret ordonna la cessation immédiate des fonctions du bureau permanent des États. Le 2 août, celui-ci déclara effectivement abandonner sa tâche. Les deux ecclésiastiques et les deux nobles du bureau cédèrent leurs pouvoirs aux deux députés du Tiers État, accompagné du greffier Louis Hubert, pour procéder à l'inventaire et à la remise des papiers de leur administration. Le ministre Lambert enjoignit cependant le bureau de poursuivre ses activités, tant que le décret n'était pas revêtu de la sanction du roi. Il engagea par ailleurs le procureur syndic du département du Nord à se rendre à Cambrai «afin d'arrêter le directoire du district qui prétendait s'emparer dès à présent de l'administration » (51). Au terme de cette mission, le département encouragea le district à reconnaître le bureau permanent du Cambrésis :

"Vous savez que la chose publique ne peut souffrir aucun intervalle, aucune interruption de service. Vous savez que deux corps différents ne peuvent pas administrer simultanément. » (52)

Le 9 août, le département prit la résolution de reconnaître les pouvoirs de cette instance concurrente jusqu'au 15 septembre. La cohabitation des deux exécutifs à Cambrai provoquait une situation explosive.

L'impatience des élus à administrer leurs circonscriptions se fit encore sentir lorsque la passation des pouvoirs devint imminente. Ils tarabustèrent les anciens administrateurs pour obtenir dans les délais, comptes, rôles d'imposition, registres, plans, devis, archives, toutes pièces nécessaires à l'exercice de leurs fonctions. Quelques élus de la Côte-d'Or voulurent par exemple prendre connaissance de l'état des recettes de la province et écrivirent pour cela des lettres particulières, sans caractère officiel (53). D'autres, de l'Hérault, posèrent les scellés précipitamment sur les papiers de l'Intendance du Languedoc, empêchant le premier secrétaire, Vialla, de remplir les ordres pour la remise de ces documents (54). Dans l'ensemble, nous le verrons, la transition administrative ne fut guère réussie.

(50) A.D.N., C 15911 , lettre du 24 juillet 1790, et C 15916.

(51) A.N., H1 701, pièce 59, billet du Contrôle général, 5 août 1790.

(52) A.D.N., L 455, lettre du baron d'Esquelbecq, 5 août 1790; C 18169 , séance du 10 août 1790 .

(53) A.N., H1 2011, pièce 36, lettre du vicomte de Bourbon-Busset, 17 juin 1790.

(54) Ibid., H1 9972, pièce 110, lettre de Ballainvilliers, 30 septembre 1790. 


\section{Démissions et révocations}

Dans ces conditions, les appels au devoir formulés par le gouvernement furent de moins en moins entendus par les administrateurs provinciaux. Au cours de l'été 1790, beaucoup d'entre eux cherchèrent à quitter leurs fonctions, sans attendre les dates fatidiques des 15 septembre et 1er octobre. Un membre de la commission provisoire du Languedoc formula ainsi son vœu de départ :

«S'y j'avois été prévenu, Monsieur, que je devois être l'un des membres de la commission, je vous aurois prié d'accepter ma démission, mais n'en ayant reçu l'annonce de votre part qu'au moment du départ, je considérais que s'y plusieurs autres membres s'excusoient aussy, l'imposition seroit retardée et elle ne l'étoit déjà que trop, ce qui me décida à faire le sacrifice d'un mois qu'il me falloit au plus pour remplir l'objet annoncé. S'y j'avois pu prévoir que le travail qu'on y additionneroit me retiendroit icy quatre mois, il auroit été de mon devoir de m'excuser. " (55)

Malgré leur rémunération de 15 livres par jour de travail, la lassitude gagnait les commissaires. Mais ce furent surtout les conflits d'administration entre exécutifs provinciaux et départementaux qui décidèrent l'Assemblée nationale à mettre fin rapidement à l'exercice des premiers. Le 10 juillet, prenant acte des difficultés survenues entre les départements et les Élus généraux de Bourgogne, celle-ci révoqua les anciens administrateurs. Elle leur défendit de «s'immiscer ni directement ni indirectement dans aucune partie de l'administration » et les exhorta à rendre compte sans délai des affaires dont ils avaient la charge (56). Un contentieux entre les deux exécutifs à propos de la construction du canal du Charolais avait précipité cette décision. Ce canal, conçu et entrepris par les États de la province, faisait la fierté des anciens administrateurs. Ceux-ci avaient fait valoir que son achèvement ne pouvait souffrir de retard sous peine de voir se multiplier les dégradations. Pour accélérer la fin des travaux, l'Assemblée nationale avait donc décrété, le 8 mai 1790, l'affectation d'une somme de 600000 livres, et confié aux membres du département de Saône-et-Loire la coordination des travaux. Cependant, les Élus de Bourgogne jugèrent que cette administration devait revenir au commissariat général des départements et tardèrent à livrer les plans, cartes, devis et autres mémoires au département désigné. Le décret du 30 juillet suivant mit fin, comme nous l'avons vu, aux activités du bureau des États du Cambrésis, tandis que la commission provisoire du Languedoc cessa ses fonctions le 17 octobre.

(55) Ibid, H1 997, pièce 54, lettre de M. Chauliac, 20 août 1790.

(56) Archives parlementaires, première série, tome XVII, p. 35. 


\section{L'échec de la transition administrative}

Pour évaluer l'efficacité de la transition administrative, nous prendrons en considération trois éléments : le recouvrement fiscal, la remise des comptes et la transmission des papiers.

\section{Un recouvrement fiscal quasi nul en 1790}

Pour avoir une idée du recouvrement fiscal de 1790 dans les anciennes provinces d'États, on peut se référer à une enquête du ministère des finances conservée aux archives nationales (57). Celui-ci voulut en effet savoir ce que les pays d'États avaient rapporté au cours des huit premiers mois de 1790 et s'adressa pour cela aux receveurs généraux des finances d'une part, et aux anciens trésoriers des États provinciaux d'autre part. Les premiers n'avaient encore pas trop à rougir du résultat de l'exercice 1790 . Certes, le recouvrement avait pris du retard, mais l'on espérait bien le combler dans l'année. À titre d'exemple, voici un état de ce qui avait été versé aux recettes générales de Provence et de Bourgogne en octobre 1790, comparé avec les versements de 1789 :

\begin{tabular}{|l|l|l|l|}
\hline \multicolumn{2}{|c|}{ PROVENCE } & \multicolumn{2}{c|}{ BOURGOGNE } \\
\hline \multicolumn{1}{|c|}{$\mathbf{1 7 8 9}$} & \multicolumn{1}{|c|}{$\mathbf{1 7 9 0}$} & \multicolumn{1}{c|}{$\mathbf{1 7 8 9}$} & \multicolumn{1}{c|}{1790} \\
\hline Février $: \mathbf{1 8 1}$ 0311. & Février $: \mathbf{1 8 1} 9861$. & Février $: 1205241$. & Février $: 1354431$. \\
\hline Mai $: 2112681$. & Mai $:-$ & Mai $: 1205241$. & Mai $: 1354431$. \\
\hline Août $: 2112681$. & Août $:-$ & Août $: 1205241$. & Août $: 1354431$. \\
\hline Novembre $: 2112681$. & Novembre $:-$ & Novembre $: 1354431$. & Novembre :- \\
\hline
\end{tabular}

L'on voit bien que les opérations étaient moins avancées en Provence qu'en Bourgogne. Néanmoins, le receveur général d'Aix, Louis Maximilien Noguier, avait au moins rentré quelque argent au début de l'année, ce qui était loin d'être le cas des trésoriers des États provinciaux. Or, dans les pays d'États, ces derniers, comptables de toute la fiscalité directe notamment, fournissaient en temps ordinaire beaucoup plus que les recettes générales à la monarchie. Voici ce que le gouvernement attendait des provinces d'États pour les huit derniers mois de 1790 : 


\begin{tabular}{|l|l|r|}
\hline LANGUEDOC & Trésorerie & 36103251. \\
& Recette générale & 3485661. \\
\hline BRETAGNE & Trésorerie & 26891871. \\
& Recette générale & 144691. \\
\hline BOURGOGNE & Trésorerie & 21979811. \\
& Recette générale & 2715481. \\
\hline PROVENCE & Trésorerie & 5417531. \\
& Recette générale & 6713361. \\
\hline PAU, BAYONNE & Recette générale & 5206301. \\
ET FOIX & & $\mathbf{1 0 8 6 5 7 9 5 ~ 1 .}$ \\
\hline TOTAL & & \\
\hline
\end{tabular}

La monarchie souffrit du défaut de recouvrement des impôts directs. Celui-ci fut total. En octobre 1790, rien n'avait encore été versé au trésor royal. Le trésorier des États de Bourgogne fut on ne peut plus clair : « l'imposition de 1790 n'est encore nullement faite. La répartition entre les départements ne l'est pas même encore » (58). Les administrateurs provisoires de la Bretagne, du Languedoc, de la Provence ou des pays pyrénéens n'avaient pas davantage procédé au recouvrement des fonds destinés aux caisses royales. Seuls les pays d'États du Nord semblaient avoir à cette date rempli leurs devoirs, d'après la réponse du subdélégué François Claude Pajot, chargé de l'intendance de Lille :

«Les recouvrements ont toujours été en activité dans ces provinces et ils n'ont pas éprouvé les difficultés ni les entraves qui, dans d'autres provinces, ont suspendu ou arrêté les différentes branches de perception. " (59)

Pour ce qui concerne 1790, trois raisons expliquent l'impéritie des administrateurs chargés de la fiscalité. La première est contenue dans la lettre citée ci-dessus : par «difficultés » ou «entraves», Pajot entendait en effet l'intégration des biens privilégiés dans les rôles d'imposition. D'après lui, la levée des impôts fut aisée dans le Nord, parce que ces biens y étaient déjà connus. Inversement, la Bourgogne eut bien du mal à recenser les biens privilégiés. Les Élus généraux durent rédiger plusieurs instructions à l'adresse des communautés pour tenter d'uniformiser les relevés. De même, on constatait en Languedoc d'importantes difficultés d'application des décrets de l'Assemblée nationale sur les impositions de 1789 et de 1790 car certaines communautés avaient intégré dans les rôles les biens privilégiés, tandis que d'autres s'étaient abstenues... Il est vrai que l'Assemblée nationale modifia

(58) Ibid, lettre de Rigoley de Montigny, 22 octobre 1790.

(59) Ibid., lettre de Pajot, 26 octobre 1790. 
plus d'une fois les règlements fiscaux, maintenant ceux de l'Ancien Régime pour les roturiers par le décret du 16 octobre 1789 , mais précisant le 28 novembre que les cotes supplétives devaient être enregistrées au lieu où les biens étaient situés. Ces difficultés furent telles qu'en septembre 1791, le gouvernement se plaignit encore car seul le district de Lodève avait envoyé les rôles des biens privilégiés pour 1789 et 1790 et ceux de Saint-Pons, Béziers, Montpellier et Mirepoix, le relevé des rôles de 1789 seulement (60). La deuxième raison tenait au fait que les États provinciaux s'étaient largement endettés pour le compte du roi à la fin de l'Ancien Régime (61). Les maigres recettes constituées étaient dès lors absorbées par le paiement des arrérages, en Bourgogne et en Languedoc notamment (62). La troisième raison concernait enfin l'incapacité des administrateurs à contraindre les citoyens. Malgré les dispositions prises pour les biens privilégiés, les impôts de 1789 et 1790 revêtaient la même forme que sous le régime «du despotisme ministériel ", pour reprendre les termes de l'époque. Or, l'Assemblée nationale avait annoncé une refonte complète de la fiscalité. Les contribuables devenaient donc récalcitrants à l'idée de se plier une année de plus aux exigences jugées iniques des administrateurs. Ceux-ci, au demeurant, ne pouvaient plus faire valoir leur autorité. Certes, les Constituants avaient tenté de devancer ces difficultés, puisque par l'article 2 du décret du 30 janvier 1790 il était précisé :

«Attendu que les contribuables seront soulagés dans l'année présente par la contribution de ci-devant privilégiés, qui tourne à leur décharge, les trésoriers ou receveurs généraux seront tenus de leur côté toutes les diligences pour que les impositions de 1790 et des années antérieures soient acquittées entièrement dans les six premiers mois de l'année 1791 au plus tard.» (63)

En d'autres termes, on espérait que l'imposition des privilégiés amènerait les contribuables à régler plus promptement leur quote-part. Cependant, pour éviter toute contradiction avec le décret du 22 décembre, l'Assemblée nationale signifia dans l'article suivant que les contraintes seraient visées par les directoires des districts. Or, dans les pays d'États, trésoriers et receveurs dépendaient des anciennes administrations à qui l'on avait ordonné de rendre les rôles exécutoires. Ainsi, jusqu'à la formation effective des départements et districts, les bases de l'autorité fiscale en province demeuraient contestables. Comment obéir aux ordres des anciens agents des États provinciaux? Lorsque ceux-ci engageaient leurs adminis-

(60) Ibid., $\mathrm{H}^{1} 995$, pièce 31 , note.

(61) Marie-Laure LEGAY, «Les emprunts des États provinciaux pour le compte du roi : le crédit des provinces au secours de l'État (France, XVIII' siècle) ", dans Pourvoir les finances en province sous l'Ancien Régime, Comité pour l'histoire économique et financière de la France, 2002.

(62) A.N., H1 $^{1} 1469$, pièce 19 , note.

(63) Archives parlementaires, première série, tome XI, p. 397. 
trés «à transiger avec les contrariétés que peut leur occasionner encore pendant quelques mois l'inégalité de la répartition » (64), ils ne pouvaient qu'être difficilement entendus. En Artois, les receveurs particuliers des anciens États, maintenus par le département du Pas-de-Calais, interrogèrent les nouveaux administrateurs sur la possibilité de contraindre les collecteurs et les gens de loi pour le recouvrement des impositions de 1790 (65). Ils n'étaient plus secondés comme auparavant par les cavaliers de la maréchaussée des États et se retrouvaient en conséquence débiteurs d'importantes sommes. Dans le Cambrésis, les villages refusèrent d'obéir aux agents des États. En janvier 1790, une insurrection relative aux impôts sur la bière sévit; en mai 1790, l'impôt sur l'eau-de-vie fut largement contesté dans toute la province. Les officiers municipaux de Beauvois refusèrent d'accompagner les commis du fermier des octrois dans leurs visites domiciliaires. Pour les contraindre à respecter les règlements des États, le bureau permanent réitéra ses ordres, puis, face au refus obstiné d'obéir, prononça deux emprisonnements à l'encontre des officiers municipaux, tandis que l'official, juge ordinaire de Cambrai, condamna ces derniers à une amende de 25 florins (66). La municipalité de Beauvois fit appel de la décision de l'official au Parlement de Douai, où elle fut défendue par l'avocat Merlin, et rédigea une pétition signée d'une quarantaine de personnes et remise en pleine séance du bureau permanent le 8 mai 1790. Cette pétition faisait notamment connaître que les États «ne pouvaient plus être considérés que comme les agents d'un pouvoir actuellement inconnu dans tout le royaume $"(67)$.

Cette affaire révèle, s'il en était encore besoin, à quel point l'autorité fiscale avait besoin d'être rétablie en cette année 1790. Au demeurant, la situation dans les anciens pays d'élections était sensiblement la même : les commissions intermédiaires y furent également confrontées à la mauvaise volonté des municipalités, qui ne prêtaient qu'une attention discrète aux objurgations. En Auvergne par exemple, la liquidation des impôts d'Ancien Régime exigea quatre années (68). Au cours de cette période, de nombreuses contestations, tant à propos des impôts supplétifs que des dîmes ou des octrois... furent enregistrées.

(64) A.N., H1 2011, pièce 41 : Nouvelle instruction concemant la confection des rôles de supplément des ci-devant privilégiés pour les six derniers mois de l'année 1789, s.l.n.d., [juin 1790], p. 5.

(65) Ibid., $\mathrm{H}^{1}$ 61-64, pièce 304 , lettre des administrateurs du département du Pas-de-Calais, 28 décembre 1790 . 15918 .

(66) Ibid., H1 664, pièces 101 à 110 sur cette célèbre affaire de Beauvois; A.D.N., C 15 916, 15917 et

(67) A.D.N., C 15 916, lettre des députés du bureau des États, 11 mai 1790.

(68) Robert SCHNERB, Les contributions directes à l'époque de la Révolution dans le département du Puy-de-Dôme, Paris, 1933, pp. 88-91. 


\section{Des comptes non établis}

Le décret du 28 décembre 1789 réglait de façon générale que les anciennes administrations devaient rendre leurs comptes aux nouvelles. II indiquait que, dans les départements où des trésoriers et des receveurs avaient été établis par les provinces, ces derniers feraient de même. Cependant, il fallut très vite donner des directives plus précises. Pour les comptes définitifs des impositions de l'Ancien Régime, y compris celles de l'année 1790, on fixa le terme de 1792 (69). Responsables sur leurs propres deniers, les trésoriers et receveurs concernés ne tardèrent pas à présenter le résultat de leur gestion. Dans le Languedoc, les comptes de la ferme de l'équivalent furent arrêtés le 1er avril 1790. Dans le Pas-de-Calais, les receveurs de l'ancienne province d'Artois rendirent leurs comptes pour les exercices de 1788 et 1789 en décembre 1790, délai qui restait raisonnable (70). Au demeurant, l'Assemblée décréta en avril 1790 que les administrateurs comptables, trésoriers ou receveurs des anciens pays d'États ne pouvaient prétendre être élus membres des nouvelles administrations avant d'avoir arrêté leurs comptes (71).

Quant aux comptes des administrations, on espérait qu'ils se feraient en temps utile, lors de la formation des directoires des nouvelles instances. Cependant, il apparaît que les États provinciaux se dispensèrent pratiquement tous de cette obligation. En Flandre wallonne, les grands baillis firent savoir en août 1790 au directoire du département du Nord que «les comptes ne pourraient être rendus qu'à une époque fort reculée qu'on ne pouvait pas même encore fixer" (72). De même en Bourgogne, les États provinciaux n'avaient toujours pas fait état de leur gestion au mois de novembre (73). Le commissariat narra par le détail les menaces dont il dut user, sans résultat. Les commissaires siégèrent en effet à partir du 7 juillet au palais des États et invitèrent le même jour les Élus à rendre le compte auquel ils étaient tenus. Le 8, le vicomte de Bourbon-Busset se présenta et assura que les comptes demandés seraient prêts sous peu de jours. Le 23 juillet, ne voyant toujours rien venir, les commissaires prièrent de nouveau les Élus. Le 24 , une délibération de ces derniers leur parvinrent, précisant que les anciens administrateurs ayant suspendu leurs fonctions le 22 juillet, il fallait s'adresser désormais au vicomte de Bourbon-Busset. Ce dernier se rendit donc le 27 juillet dans la chambre des commissaires pour remettre un mémoire annonçant qu'un délai de deux mois serait nécessaire pour rendre les comptes. Le commissariat réagit vivement en arrêtant un délai de 8 jours seulement. Le 6 août, à l'expi-

(69) Archives parlementaires, première série, tome XI, p. 397, article 6 du décret du 30 janvier 1790.

(70) A.N., H1 61-64, pièce 304, lettre des administrateurs du département du Pas-de-Calais, 28 décembre 1790.

(71) Lettres patentes du 20 avril 1790, article 2.

(72) A.N., H1 701, pièce 35, avis du directoire du département, 21 septembre 1790.

(73) Ibid., D IV 24, mémoire au Comité de constitution. 
ration du délai fixé, deux membres du commissariat se transportèrent chez le vicomte pour connaître sa dernière détermination. Celui-ci répondit que l'Assemblée nationale avait été saisie de l'affaire et qu'il fallait attendre un nouveau décret de sa part fixant la conduite des uns et des autres. De fait, le 16 août, les commissaires reçurent le décret du 10 juillet 1790 mettant fin aux fonctions des Élus et précisant que les comptes seraient rendus sans délai. Ils notifièrent ce décret au vicomte de Bourbon-Busset qui cependant resta silencieux. En conséquence, les commissaires prirent un arrêté le 23 août pour supplier l'Assemblée nationale de déterminer la responsabilité qu'encourent les anciens Élus. Celle-ci, par son décret du 1er octobre, enjoignit tous les comptables à rendre leurs comptes dans les huit jours sous peine d'être poursuivis comme débiteurs. Cependant, le vicomte se justifia par un mémoire envoyé au comité de finances et ce dernier interpréta le décret du 1er octobre en indiquant que l'Assemblée nationale n'avait point entendu ordonner l'impossible et que le compte à rendre dans la huitaine devait être entendu dans le cas où il se trouverait être achevé! Trompés dans leur attente, les commissaires firent citer les anciens Élus, en la personne du vicomte de BourbonBusset, devant un bureau de conciliation le 28 et 30 janvier 1791. Le vicomte promit le compte pour le 1er mars, mais partit entre-temps pour l'armée. Le 8 février, les commissaires mirent fin à cette affaire en arrêtant que les ci-devant Élus étaient redevables d'une somme de 800000 livres (74). Ainsi, les comptes définitifs des États provinciaux de Bourgogne ne furent-ils jamais établis.

L'on comprend que les anciens agents avaient quelques réticences à livrer à l'opinion publique le bilan comptable de leur administration. En Flandre maritime, la commission formée spécialement pour enquêter sur les comptes de la province, ne manqua pas d'imprimer le résultat de ses recherches et de dénoncer les importants émoluments que s'octroyait l'agent principal de la province :

«Presque partout, les administrateurs, pour qui toutes ces différentes administrations semblent avoir été créées, et qui ne connoissent d'autres règles que leur volonté, sont parties prenantes, et l'on voit que l'intendant chargé de surveiller ces administrations, n’a pas dédaigné cette qualité... Cette administration est abusive par sa nature, en ce qu'elle est dirigée par Monsieur Lenglé de Schoebeque, subdélégué général de l'intendant, qui réunit toutes les charges, qui donne des ordonnances sur le trésorier du département, sans qu'aucun des officiers municipaux nommés par l'intendant n'ose contredire. " (75)

On voit par là que la transition administrative recouvrait bien dans les anciens pays d'États un enjeu politique encore vivement ressenti en $\mathbf{1 7 9 0 .}$

(74) Ibid., $\mathrm{H}^{1}$ 20122 $^{2}$, pièce 23, procès-verbal des séances du commissariat, 8 février 1791.

(75) Ibid, $\mathrm{H}_{1}$ 701, pièce 8, Extrait des comptes des anciennes administrations de la Flandre maritime, 1790 , pp. 3 et 4. Mémoire rédigé par l'abbé LEGIER, chanoine de la collégiale Saint-Pierre-de-Cassel. 


\section{Des papiers mal transmis}

De ce point de vue, la remise des papiers constituait également une désagréable obligation pour les anciens administrateurs. Les archives de l'intendance du Languedoc, par exemple, représentaient à elles seules vingt-cinq à trente charretées (76). Plusieurs problèmes se posaient. Le tri, en premier lieu, inquiéta les responsables. Si certains papiers trouvaient aisément leurs destinataires, d'autres méritaient un soin particulier. À Montpellier, on se demanda à qui confier les correspondances des États ou de l'intendant avec les ministres, les papiers relatifs aux fixations des limites de la France avec le Comtat-Venaissin, ceux relatifs aux anciennes querelles de religion, aux procès contre les protestants ou encore ceux concernant l'établissement des vingtièmes lors de la régie de 1752 à 1756... Dans le Nord, on fit attention, dans les différentes administrations, à bien séparer les pièces relatives à la navigation et aux ponts et chaussées, afin de les transmettre toutes au directoire du département (77). À Dijon, on jugea qu'en attendant de diviser les papiers entre les trois départements, il pouvait être judicieux de les conserver tous au greffe des anciens États de Bourgogne et de ne délivrer que des copies, tant aux départements qu'aux districts (78)

Les administrateurs se plaignirent par ailleurs de la confusion qui régnait à l'occasion de la remise de ces papiers. Les procès-verbaux de cette transmission n'étaient pas toujours dressés. Enfin, la suspicion régnait. On soupçonnait les anciens agents de vouloir conserver leurs archives. "Jusqu'à ce moment, les anciennes administrations ne se sont pas prêtées à laisser faire l'inventaire de leurs papiers ", écrivit le directoire du département du Nord en septembre 1790. Le retard pris par la remise des papiers entraîna le report du premier conseil de ce département au 3 novembre (79) Néanmoins, les administrateurs du district de Douai signalaient encore le 4 janvier 1791 que « leurs connaissances sur l'ancienne administration des États étaient presque nulles par le défaut de remises des titres, comptes et autres pièces » (80).

Au terme de cette étude, une conclusion s'impose : grâce à la vigilance de l'Assemblée constituante, les attributions essentielles de l'État continuèrent d'être exercées dans les provinces : l'autorité fiscale fut maintenue, les rentes payées, les ouvrages publics entretenus... La lecture des débats de l'Assemblée révèle la lucidité des députés, très informés des événements qui se déroulaient dans leurs provinces respectives. Chacun, pour ce qui le concernait, faisait état

(76) Ibid., $\mathrm{H}^{1}$ 995, pièce 64, note, juillet 1790.

(77) A.D.N., C 15 919, lettre de Lagarde à Messieurs Descamps et Béthune, commissaires du département du Nord à Cambrai, 12 août 1790.

(78) A.N., H1 2011, pièce 46, mémoire.

(79) A.D.N., L 764, mémoire adressé à l'Assemblée nationale par les administrateurs composant le directoire du département du Nord, septembre 1790.

(80) lbid., L 7200, lettre du 4 janvier 1791. 
à Paris de la situation de sa région et sollicitait en temps utile les décrets nécessaires au maintien de l'ordre. Dès lors, aucun pays ne souffrit d'une vacance du pouvoir intermédiaire et les municipalités surent toujours à qui adresser leurs requêtes, notamment entre la fin de l'année 1789 et l'automne 1790, période au cours de laquelle le risque d'anarchie fut le plus sensible. Les Constituants n'avaient cependant pas prévu une transition si chaotique du pouvoir dans les provinces d'États. Leurs décrets entrainèrent en effet des situations intenables : la cohabitation des exécutifs provinciaux et départementaux provoqua pendant quelques mois à Cambrai, à Dijon, à Montpellier, des tensions politiques auxquelles il fallut remédier. C'est ainsi qu'après avoir vivement encouragé les anciens administrateurs à se maintenir dans l'exercice de leurs attributions, les députés de l'Assemblée nationale durent sèchement mettre fin à leurs prérogatives, en leur interdisant du jour au lendemain toute immixtion dans les affaires locales. Les circonstances commandaient. Dans la mesure où les anciens agents provinciaux ne prétendaient guère conserver leurs fonctions au-delà du temps nécessaire, la transition politique fut néanmoins, comme dans les anciennes provinces d'élections, relativement aisée.

Sur le plan administratif en revanche, la transition de l'été 1790 ne fut guère satisfaisante. Le contexte n'avait pas encouragé les anciens administrateurs à la préparer avec ardeur. Ils eurent toutes les difficultés du monde à faire établir les rôles d'imposition de 1789 et 1790, et à procéder au recouvrement. Une fois révoqués, leur désintérêt grandit. Personne ne procéda à l'établissement des comptes des anciens États provinciaux et les papiers furent transmis avec difficulté. Les agents provinciaux n'étaient cependant pas seuls en cause. Les commissaires départementaux ne s'activèrent pas davantage pour faciliter cette transition. Le pouvoir central jugea très insatisfaisant le travail effectué par les commissariats institués par le décret du 22 décembre 1789. Il observa que les commissaires du Languedoc n'avaient «presque rien fait d'utile pendant un si long intervalle», puisque ni les impôts, ni les comptes, ni les dettes, ni les anciennes affaires de la province n'avaient été liquidés au terme de leur mission, qui avait duré presque un an (81). Dès lors, il encouragea les députés du Languedoc à l'Assemblée à provoquer un décret pour qu'il fût pris d'autres mesures plus efficaces. La liquidation des affaires provinciales devenait une véritable corvée pour les membres des directoires qui préféraient se consacrer aux affaires des nouvelles administrations. La province n'avait vraiment plus, cette fois-ci, de raison d'être.

Marie-laure LEGAY Université Charles-de-Gaulle Lille III UFR d'Histoire, BP 149 59653 Villeneuve d'Ascq marie-laure.legay@wanadoo.fr

(81) A.N., H1 995, pièces 31 et 47, septembre 1791. 


\section{CHRONOLOGIE}

\section{9}

4 août : suppression des privilèges provinciaux.

23 et 25 septembre : décrets relatifs à la contribution des ex-privilégiés pour les six derniers mois de 1789.

6 octobre : décret sur la contribution patriotique.

10 octobre : réunion de la noblesse du Languedoc à Toulouse. Convocations des trois ordres du Dauphiné et de la noblesse bretonne annoncées pour les jours suivants.

15 octobre : décret portant sur l'élection des suppléants à l'Assemblée nationale : le vote de l'ensemble des citoyens inscrits sera désormais sollicité (suppression du vote par ordre dans les assemblées de bailliages et de sénéchaussées).

17 octobre : instructions aux commissions intermédiaires pour l'exercice fiscal de 1789.

26 octobre : décret interdisant toute convocation par ordre et toute assemblée d'États dans le royaume.

27 octobre : proclamation du roi confiant aux commissaires ordinaires des diocèses du Languedoc la contribution patriotique et les rôles supplémentaires des biens privilégiés.

2 novembre : décret sur la vente des biens ecclésiastiques. Larticle 10 prévoit que les dîmes seront perçues par les administrations provinciales et municipales, en déduction des charges imposées aux classes les moins aisées.

3 novembre : décret ajournant les parlements.

9 novembre : réunion du bureau des États du Cambrésis, enfreignant le décret du 26 octobre.

24 novembre: déclaration de l'Assemblée nationale annulant la délibération du 9 novembre du bureau des États du Cambrésis.

28 novembre : décret sur les cotes supplétives.

14 décembre : décret créant les municipalités et leur cédant le soin d'établir les rôles d'imposition.

22 décembre (et lettres patentes de janvier 1790) : décret relatif aux assemblées administratives du royaume, prévoyant notamment la cessation d'activités des États provinciaux, assemblées provinciales et assemblées inférieures le jour où les administrations de département et de district seront formées (section III, article 8). Le décret organise en Bretagne, Bourgogne, Languedoc et Provence, des «commissariats de départements " chargés d'assurer la transition administrative (section III, article 10).

28 décembre : décret annonçant que les États provinciaux, assemblées provinciales, commissions intermédiaires, intendants et subdélégués devront rendre aux administrations qui les remplaceront le compte des fonds, pièces, et papiers relatifs à chaque département. 
Janvier : lettres patentes sur la constitution des assemblées administratives (voir décret du 22 décembre 1789).

21 janvier : lettres patentes sur décret autorisant les commissions intermédiaires des pays d'États à rendre exécutoires les rôles d'imposition.

28 janvier : décret ordonnant la perception des aides et octrois de toute nature, dans les mêmes formes qu'auparavant.

30 janvier (et lettres patentes du 3 février) : décret relatif aux recouvrements et versements des impositions de 1790 , ordonnant notamment que les préposés aux recouvrements verseront les fonds dans les mains des receveurs ordinaires des provinces, "chargés dans les années précédentes de la perception des impositions ». Par ailleurs, les trésoriers des pays d'États ou les receveurs généraux des finances ne sont tenus de rendre leurs comptes en règle qu'en 1792, par devant le tribunal qui sera désigné à cet effet.

3 février : lettres patentes relatives aux recouvrements et versements des impositions de 1790 (voir décret du 30 janvier).

14 février : proclamation du roi sur les impositions dans les provinces d'Artois, de Flandres, du Cambrésis et du Hainaut, stipulant que les rôles seront rendus exécutoires en la forme qui a été suivie jusqu'à présent par les anciens administrateurs de ces provinces, lesquels feront comme par le passé, la répartition et le recouvrement desdites impositions (article 3).

21 février : lettres patentes ordonnant que, pour les pays de Bresse, Bugey et Gex, l'assiette des impositions de 1790 soit confiée aux trésoriers généraux de France en Bourgogne, assistés des syndics et des officiers des élections desdits pays.

26 février (et lettres patentes du 4 mars) : décret fixant la nouvelle division du royaume. L'article 4 stipule : «la division du royaume en départements et districts n'est décrétée quant à présent que pour l'exercice du pouvoir administratif, et les anciennes divisions relatives à la perception des impôts et au pouvoir judiciaire subsisteront jusqu'à ce qu'il en ait été autrement ordonné ».

4 mars : lettres patentes sur la nouvelle division du royaume (voir ci-dessus).

10 mars : décret ordonnant que les anciens procureurs des pays de Provence continueront d'administrer la province jusqu'à la formation des départements.

23 mars : décret formant une «commission provisoire» en Languedoc pour l'assiette des impositions de 1790. Cette commission (une commission principale à Montpellier et des commissions secondaires dans chaque diocèse) vint remplacer les « commissaires ordinaires des diocèses » et fonctionna jusqu'en octobre 1790, date à laquelle les commissaires des départements formés en Languedoc sont entrés en exercice.

1er avril : arrêt des comptes de la ferme de l'Équivalent, en Languedoc : 809286 livres non recouvrées.

11 avril : commission particulière adressée aux Élus généraux de Bourgogne pour la répartition des impôts de 1790, leur attribuant la faculté de statuer sur les réclamations des imposés et ordonnant que le trésorier tiendra les sommes provenant des impôts à leur disposition.

20 avril : lettres patentes annonçant, en référence au décret du 28 décembre 1789 , que les administrateurs comptables, trésoriers ou receveurs des anciens pays d'États qui n'ont pas encore rendu compte de la gestion des affaires de chaque province ou du maniement des deniers publics, ne pourront, avant l'arrêté de leurs comptes, être élus membres des administrations de département et de district. 
25 mai : décret sur la formation des suppléments de rôles pour les six derniers mois de 1789 (dernier délai).

31 mai : première séance du département de Saône-et-Loire.

28 et 30 juin : décret mettant les nouvelles administrations en activité. Ce décret prévoit les premières réunions des conseils de district le 15 septembre et celles des conseils de département le 1er octobre (article 3). L'article 2 porte plus particulièrement sur les anciennes provinces qui avaient une administration commune et organise les fonctions des commissaires de départements. Répartition et perception des impôts sont confiées aux départements.

2 juillet : lettres patentes sur le décret des 28 et 30 juin 1790 mettant les nouvelles administrations en activité.

7 juillet : première séance du commissariat des départements de Bourgogne, au palais des Etats.

10 juillet : décret révoquant les pouvoirs des Élus génëraux de Bourgogne et ordonnant qu'ils rendront compte sans délai.

20 juillet : dernière délibération des Élus généraux de Bourgogne par laquelle ils annoncent la suspension de leurs fonctions au 22 juillet.

30 juillet : décret révoquant les députés ordinaires des États du Cambrésis.

1er août : réception des instructions pour le département de Haute-Marne.

2 août : fin des activités du bureau des États du Cambrésis.

13 août : réception des instructions pour le département Rhône-et-Loire.

15 septembre : première séance du commissariat des départements du Languedoc. Entrée en activité officielle des conseils de district.

28 septembre : réception des instructions pour le département de Haute-garonne (Languedoc).

30 septembre : suppression des parlements de province.

1er octobre : décret enjoignant aux ci-devant Élus généraux de Bourgogne et aux autres comptables de la province de rendre leurs comptes sous huitaine. Entrée en activité officielle des conseils de départements.

17 octobre : cessation des activités de la commission provisoire du Languedoc.

3 novembre : première séance du département du Nord.

\section{1}

28 et 30 janvier : citation des ci-devant Élus généraux de Bourgogne devant le bureau de conciliation.

8 février : les commissaires des départements de Bourgogne arrêtent que les ci-devant Élus généraux sont redevables d'une somme de 800000 livres.

20 mars (décret du 8 mars) : loi relative aux employés des anciennes administrations.

12 avril : décret sur les dettes des pays d'États, déclarées dettes nationales.

14 septembre : décret portant réunion d'Avignon et du Comtat Venaissin à la France. Trois commissaires sont chargés provisoirement de l'organisation du territoire et de l'établissement des pouvoirs publics.

21 septembre 1791 : décret supprimant tous les commissariats des provinces d'États à compter du $1^{\text {er }}$ novembre suivant. 